\title{
Металл-усиленное фотохимическое травление N- и Ga-полярных эпитаксиальных слоев GaN
}

\author{
(C) Д.В. Мохов ${ }^{1}$, Т.Н. Березовская ${ }^{1,2}$, Е.В. Никитина ${ }^{1}$, К.Ю. Шубина ${ }^{1}$, А.М. Мизеров ${ }^{1}$, А.Д. Буравлев ${ }^{1,2,3}$ \\ ${ }^{1}$ Санкт-Петербургский национальный исследовательский Академический университет Российской академии наук, \\ 194021 Санкт-Петербург, Россия \\ ${ }^{2}$ Физико-технический институт им. А.Ф. Иоффе Российской академии наук, \\ 194021 Санкт-Петербург, Россия \\ ${ }^{3}$ Санкт-Петербургский государственный электротехнический университет „ЛЭТИ“ им. В.И. Ульянова (Ленина), \\ 197376 Санкт-Петербург, Россия \\ E-mail: dm_mokhov@rambler.ru
}

Поступила в Редакцию 23 июля 2019 г.

В окончательной редакции 29 июля 2019 г.

Принята к публикации 29 июля 2019 г.

\begin{abstract}
Представлены результаты исследования процессов фотохимического травления, осуществленных без приложения внешнего напряжения, структур с Ga- и $\mathrm{N}$-полярными слоями $\mathrm{GaN}$, синтезированными методом молекулярно-пучковой эпитаксии с плазменной активацией азота. Показано, что скорость травления слоев с разной полярностью сильно различается. При этом использование для травления слоев GaN масок на основе золота вместо титана также позволяет повысить скорость травления слоев.
\end{abstract}

Ключевые слова: слои $\mathrm{GaN}$, фотохимическое травление, металл-усиленное травление.

DOI: $10.21883 /$ FTP.2019.12.48635.9220

\section{1. Введение}

Широкозонные полупроводники, в частности $\mathrm{GaN}$, имеют огромный потенциал для создания различных электронных устройств, таких как СВЧ транзисторы, микромеханические системы (MEMS), резонаторы на поверхностных акустических волнах и др. [1-3].

Для изготовления этих устройств зачастую необходим метод получения топологического рисунка путем травления, обеспечивающий получение гладкой поверхности с контролируемой и равномерной глубиной травления.

Травление слоев $\mathrm{GaN}$ является достаточно сложной задачей из-за чрезвычайно высокой химической стойкости материала. В настоящее время жидкостное химическое травление слоев $\mathrm{GaN}$ обычно осуществляется с помощью различных методов, таких как: травление с ультрафиолетовым (УФ) облучением (фотохимическое травление) [4,5], с УФ облучением и формированием короткозамкнутого противоэлектрода на поверхности слоя $\mathrm{GaN}$ без приложения внешнего напряжения (металлусиленное фотохимическое травление) [6-13], с УФ облучением, формированием контактного противоэлектрода и приложением внешнего напряжения (фотоэлектрохимическое травление) [12,14]. В свою очередь известно, что метод металл-усиленного фотохимического травления слоев $\mathrm{GaN}$ обеспечивает получение топологического рисунка при использовании металлической защитной маски, которая одновременно служит катодом, что существенно упрощает процесс травления. Поэтому в настоящей работе были исследованы процессы травления слоев $\mathrm{GaN}$ с помощью данного метода.

Одной из задач настоящего исследования была разработка простого, воспроизводимого процесса жид- костного селективного химического травления Ga- и $\mathrm{N}$-полярных слоев $\mathrm{GaN} n$-типа проводимости, который может обеспечить полное удаление эпитаксиального слоя с кремниевой подложки без повреждения ее поверхности и гарантирует анизотропность профиля травления.

\section{2. Образцы и детали эксперимента}

В качестве электролита для травления слоев $\mathrm{GaN}$ используют водные растворы с различной концентрацией $\mathrm{KOH}, \mathrm{HNO}_{3}, \mathrm{H}_{3} \mathrm{PO}_{4}$ и других компонентов [414]. Выбор травителя обусловлен следующими критериями: 1) травитель не должен повреждать металлическую маску и поверхность $\mathrm{Si}$-подложки, 2) он должен травить при комнатной температуре, 3) травление слоя $\mathrm{GaN}$ должно происходить только на незащищенных маской областях, без бокового подтравливания под маску. Наилучшим образом этим критериям соответствует травитель на основе персульфата калия и щелочи $\left(\mathrm{K}_{2} \mathrm{~S}_{2} \mathrm{O}_{8} / \mathrm{KOH}\right)$, используемый в настоящем исследовании.

В качестве катода, выполняющего также функцию маски, используют различные металлы: Ni [8], Pt [7,9], $\mathrm{Ti}[7,10]$ и $\mathrm{Ti} / \mathrm{Pt}[4,10], \mathrm{Ni}$-пластинка с проволочным $\mathrm{Pt}$-электродом $[4,10], \mathrm{Ti} / \mathrm{Au} / \mathrm{Pt}[12]$. В данном исследовании были использованы маски Ті и $\mathrm{Au.}$

Химическое жидкостное травление нитрида галлия затруднено из-за прочной ковалентной связи $\mathrm{Ga}-\mathrm{N}$. Травление проводят при воздействии на образец нитрида галлия, на поверхность которого нанесена защитная металлическая маска (Тi- или $\mathrm{Au-маска),} \mathrm{излуче-}$ 
Таблица 1. Характеристики структур

\begin{tabular}{l|c|c|c|c|c}
\hline \multicolumn{1}{c|}{ Номер структуры } & 1 & 2 & 3 & 4 & 5 \\
\hline Описание структуры & $\mathrm{GaN} / \mathrm{Si}(111)$ & $\mathrm{GaN} / \mathrm{SiC} / \mathrm{Si}(111)$ & $\mathrm{GaN} / \mathrm{Si}_{x} \mathrm{~N}_{y} / \mathrm{Si}(111)$ & $\mathrm{GaN} / \mathrm{Si}(111)$ & $\mathrm{GaN} / \mathrm{Si}_{x} \mathrm{~N}_{y} / \mathrm{Si}_{(111)}$ \\
Толщина слоя $\mathrm{GaN}$, мкм & 0.84 & 0.88 & 0.33 & 0.58 & 0.62 \\
Полярность & $\mathrm{Ga}$-face & $\mathrm{N}$-face & $\mathrm{Ga}$-face & Ga-face & Ga-face
\end{tabular}

нием с энергией больше ширины запрещенной зоны $\left(E_{g}=3.42\right.$ эВ для $\mathrm{GaN}$ со структурой вюрцита [15]).

Известно, что при освещении протекают две индуцированные фотонами реакции (на поверхности слоя $\mathrm{GaN}$ и в растворе травителя) [5]:

1) при поглощении фотона $(h v)$ нитридом галлия происходит генерация электронно-дырочной пары на поверхности полупроводника

$$
\mathrm{GaN}+h v \rightarrow \mathrm{Ga}^{+} \mathrm{N}+e^{-}
$$

2) вследствие поглощения света персульфат-ионом $\mathrm{S}_{2} \mathrm{O}_{8}^{2-}$ разрывается О-О-связь и образуется сульфатанион-радикал $\mathrm{SO}_{4}^{*-}[16]$,

$$
\mathrm{SO}_{3}^{-}-\mathrm{O}-\mathrm{O}-\mathrm{SO}_{3}^{-} \stackrel{h v}{\longrightarrow} 2 \mathrm{SO}_{4}^{*-} \text {. }
$$

Далее электроны, генерированные в $\mathrm{GaN}$ по реакции (1), мигрируют в металл защитной маски, на поверхности которого происходит восстановление чрезвычайно активного сульфат-анион-радикала $\mathrm{SO}_{4}^{*-}$, который образовался в реакции (2), до сульфат-аниона $\mathrm{SO}_{4}^{2-}$ :

$$
\mathrm{SO}_{4}^{*-}+e^{-} \rightarrow \mathrm{SO}_{4}^{2-} \text {. }
$$

Также на поверхности металла происходит конкурирующая реакция, которая имеет достаточно большой стандартный электродный потенциал, равный +2.01 В [17]:

$$
\mathrm{S}_{2} \mathrm{O}_{8}^{2-}+2 e^{-} \rightarrow 2 \mathrm{SO}_{4}^{2-} \text {. }
$$

Кроме того, в щелочной среде происходит перенос электрона с иона гидроксила $\mathrm{OH}^{-}$к сульфат-анионрадикалу с образованием радикала гидроксила $\mathrm{OH}^{*}$ :

$$
\mathrm{SO}_{4}^{*-}+\mathrm{OH}^{-} \rightarrow \mathrm{SO}_{4}^{2-}+\mathrm{OH}^{*} .
$$

Гидроксильный радикал реагирует с растворенным в травителе кислородом с образованием озониданиона $\mathrm{O}_{3}^{-}$:

$$
\mathrm{OH}^{*}+\mathrm{O}_{2} \rightarrow \mathrm{O}_{3}^{-}+\mathrm{H}^{+} .
$$

Крайне реакционноспособный озонид-анион $\mathrm{O}_{3}^{-}$окисляет галлий до оксида,

$$
2 \mathrm{Ga}^{+} \mathrm{N}+\mathrm{O}_{3}^{-} \rightarrow \mathrm{Ga}_{2} \mathrm{O}_{3}+\mathrm{N}_{2},
$$

который в свою очередь растворяется в щелочной среде при взаимодействии с гидроксил-ионами с образованием галлат-аниона $\mathrm{GaO}_{3}^{3-}$.
Суммарная реакция растворения нитрида галлия может быть записана уравнением

$$
\begin{aligned}
2 \mathrm{GaN}+ & 3 \mathrm{~K}_{2} \mathrm{~S}_{2} \mathrm{O}_{8}+12 \mathrm{KOH} \\
& \stackrel{6 h v}{\longrightarrow} 2 \mathrm{~K}_{3} \mathrm{GaO}_{3}+\mathrm{N}_{2}^{\uparrow}+6 \mathrm{~K}_{2} \mathrm{SO}_{4}+6 \mathrm{H}_{2} \mathrm{O} .
\end{aligned}
$$

Для травления $\mathrm{GaN}$ используют водный раствор, содержащий сильный окислитель (персульфат калия) и гидроксид калия, способный надежно связывать продукты окисления в растворимой форме согласно уравнению реакции (8).

Эксперименты по травлению выполнялись на образцах структур, представляющих собой эпитаксиальные слои $\mathrm{GaN}$, выращенные на высокоомных подложках $\mathrm{Si}(111)$ методом молекулярно-пучковой эпитаксии с плазменной активацией азота (МПЭПА) на установке Veeco GEN 200 [18]. Эпитаксиальные слои GaN с Gaи $\mathrm{N}$-полярностью были выращены непосредственно на подложке $\mathrm{Si}$, либо с использованием переходных слоев $\mathrm{SiC}$ или $\mathrm{Si}_{x} \mathrm{~N}_{y}$. Все исследуемые слои $\mathrm{GaN}$ имели проводимость n-типа с концентрацией носителей заряда $n_{e} \sim 10^{-18} \mathrm{~cm}^{-3}$. Параметры исследуемых образцов представлены в табл. 1 .

Для изучения процесса металл-усиленного травления на поверхность исследуемых образцов вакуумным термическим испарением были нанесены Ті-маска толщиной 70 нм, Аu-маска толщиной 200 нм, и магнетронным напылением Ті-маска толщиной 1.0 мкм.

Травление осуществлялось в кварцевом сосуде при комнатной температуре при перемешивании раствора с помощью магнитной мешалки. Для УФ облучения образцов использовалась ксеноновая лампа Osram XBO мощностью 250 Вт.

В ходе травления поверхность образцов структур исследовали с помощью сканирующего электронного микроскопа SUPRA 25 и оптического микроскопа высокого разрешения Leica INM100, глубину травления и шероховатость поверхности измеряли с помощью механического контактного профилометра Stylus XP-1.

\section{3. Результаты и обсуждение}

Структуры на основе $\mathrm{GaN}$ были выращены на подложках $\mathrm{Si}(111)$, рассогласованных с $\mathrm{GaN}$ по параметру кристаллической решетки и коэффициенту термического расширения; несмотря на применение специальных процедур на начальных стадиях роста, они имеют до- 
Таблица 2. Результаты травления с Аu- и Ті-масками

\begin{tabular}{c|c|c|c|c|c}
\hline \multirow{2}{*}{$\begin{array}{c}\text { Номер } \\
\text { структры }\end{array}$} & \multirow{2}{*}{ Полярность } & \multicolumn{2}{|c|}{ Травление с Аи-маской } & \multicolumn{2}{|c}{ Травление с Ті-маской 1 мкм } \\
\cline { 3 - 6 } & $\begin{array}{c}\text { Скорость } \\
\text { травления, } \\
\text { нм/мин }\end{array}$ & $\begin{array}{c}\text { Шероховатость } \\
\text { поверхности Si-подложки, } \\
R_{q}, \text { нм }\end{array}$ & $\begin{array}{c}\text { Скорость } \\
\text { травления, } \\
\text { нм/мин }\end{array}$ & $\begin{array}{c}\text { Шероховатость } \\
\text { поверхнсти Si-подложки, } \\
R_{q}, \text { нм }\end{array}$ \\
\hline 1 & Ga-face & 0.71 & 13 & 0.24 & - \\
2 & N-face & 3.55 & 6.1 & 3.23 & 7 \\
3 & Ga-face & 0.83 & 12 & 0.20 & 31 \\
4 & Ga-face & 0.88 & 6.6 & 0.36 & 14 \\
5 & Ga-face & 1.62 & - & &
\end{tabular}

статочно высокую плотность дефектов. На рис. 1 показаны полученные методом сканирующей электронной микроскопии (СЭМ) изображения выращенных слоев $\mathrm{GaN}$ с наиболее характерной морфологией поверхности, на которых явно видны протяженные дефекты - поры и границы несросшихся кристаллитов. Структуры 1 и 2 имеют схожую морфологию и наименьшее количество протяженных дефектов-пор по сравнению с другими образцами (рис. 1). Структуры 3 и 4 имеют схожую морфологию поверхности, похожую на характерную для структур 5, но с меньшим количеством протяженных дефектов. На поперечном сколе структуры 5 в свою очередь видны „складки“ с наиболее ярко выраженными неплотно сросшимися доменами.

В первой серии экспериментов проводилось травление образцов структур 1 и 2 приблизительно одинаковой толщины $h \approx 0.85$ мкм, с Ga- и $\mathrm{N}$-полярностью соответственно, с использованием Ті-маски толщиной 70 нм в описанных выше условиях. Толщина титановой маски 70 нм оказалась недостаточной для полного удаления слоя $\mathrm{GaN}$ толщиной $h \approx 0.85$ мкм с подложки. В результате эксперимента было установлено, что скорость травления $\mathrm{N}$-полярного слоя $\mathrm{GaN}$ в несколько раз превысила скорость травления $\mathrm{Ga}-$ полярного слоя.
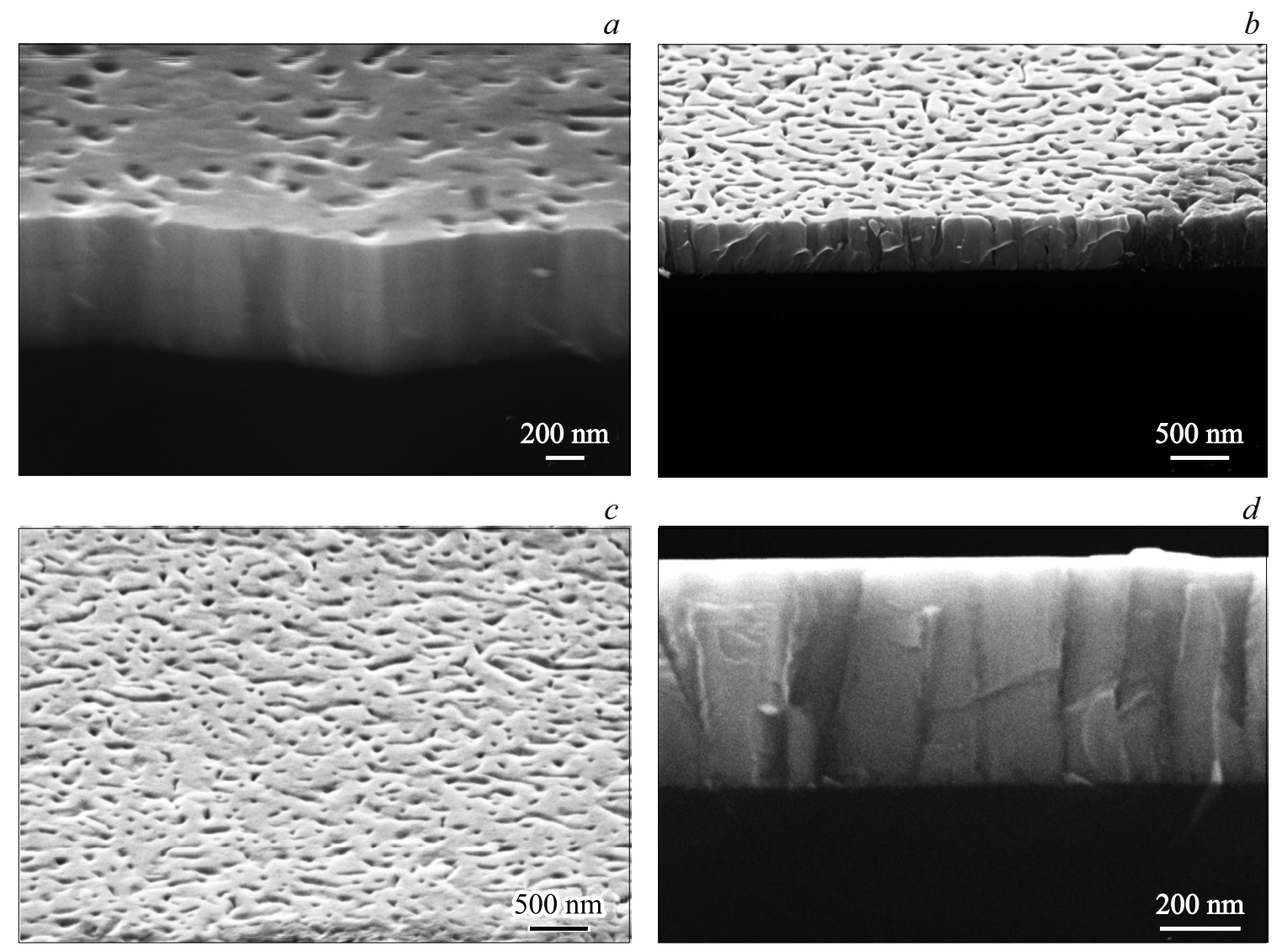

Рис. 1. СЭМ-изображения поперечных сколов и поверхности выращенных слоев $\mathrm{GaN}: a-$ структура $1, b-$ структура $5, c, d-$ структура 4. 
$a$
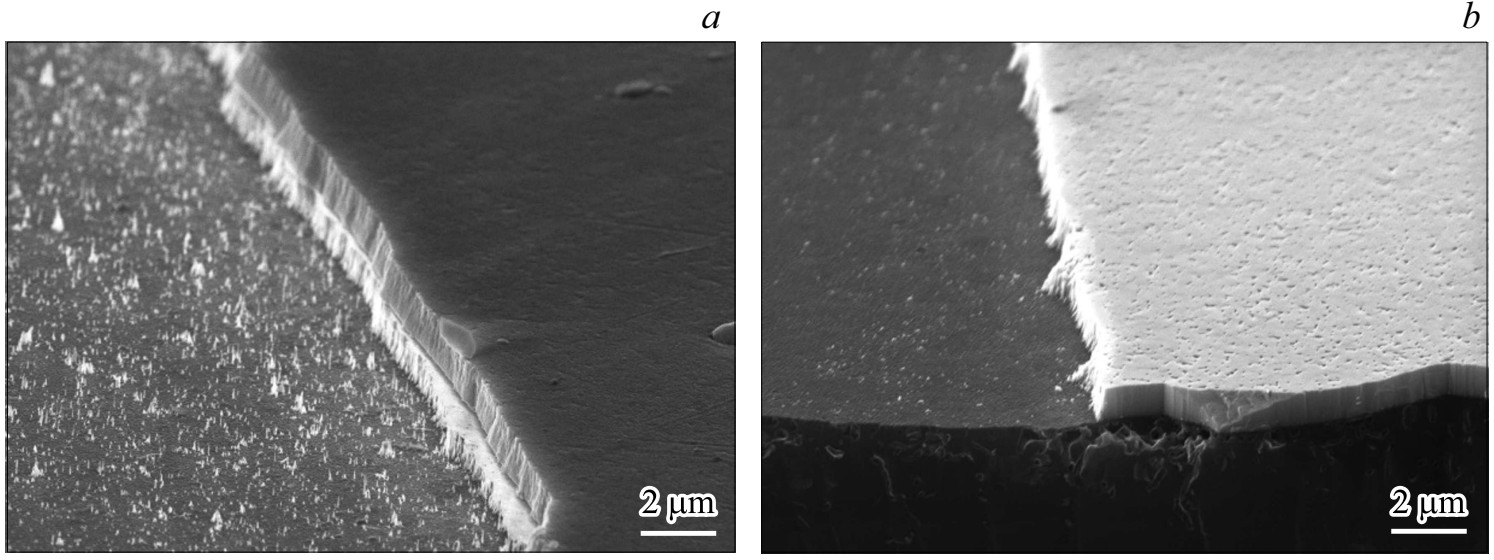

Рис. 2. СЭМ-изображения слоя $\mathrm{GaN}$ с N-полярностью (структура 2) после травления с Ті-маской толщиной 1 мкм: $a-$ Ti-маска не удалена, $b$ - Ті-маска удалена.
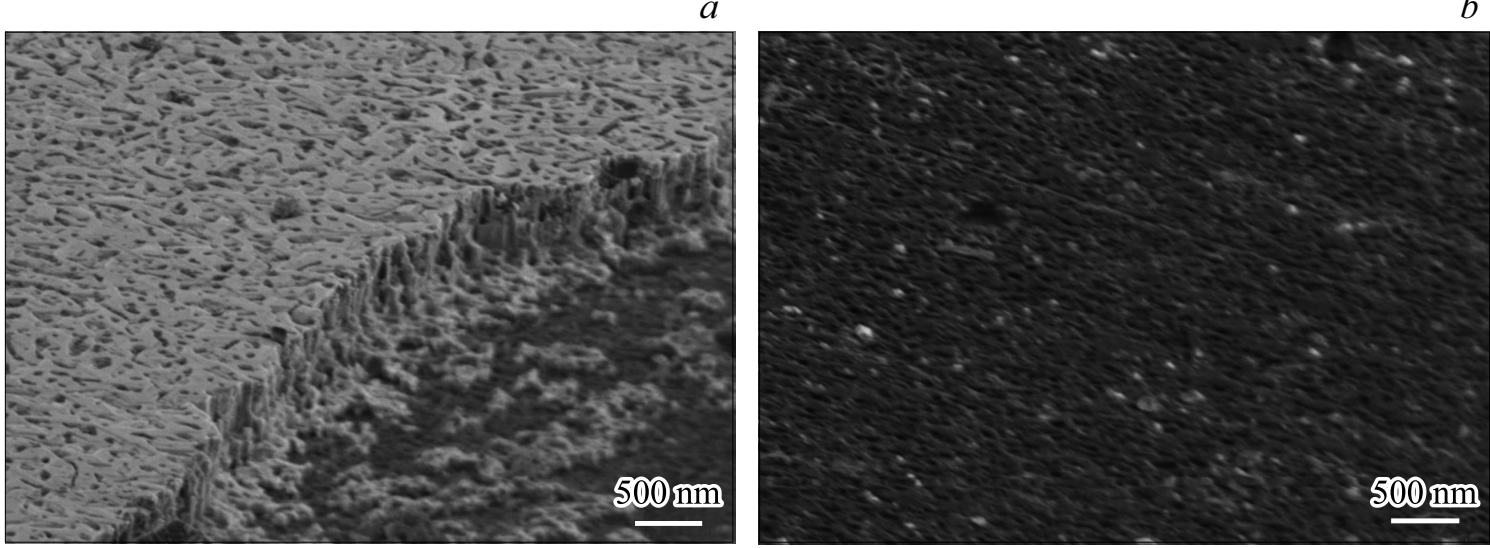

Рис. 3. СЭМ-изображения слоя $\mathrm{GaN}$ с Ga-полярностью (структура 5) после травления с Тi-маской толщиной 1 мкм: $a-$ Ti-маска удалена, снимок области образца вблизи границы травления, $b$ - вдали от границы травления.

Была проведена вторая серия экспериментов по травлению образцов пяти структур при условиях травления, описанных ранее, но с гораздо большей толщиной Ті-маски, 1.0-1.2 мкм. На рис. 2 и 3 показаны СЭМ-изображения структур с $\mathrm{N}$ - и Ga-полярностью соответственно после травления до чистой поверхности Si-подложки. Использование Ті-маски большей толщины позволяет: полностью удалить слой $\mathrm{GaN}$; получить профиль травления с вертикальными стенками, который точно повторяет профиль Ті-маски.

Исследования с помощью СЭМ поверхности Ga-полярных слоев в результате травления разной длительности показали, что после того, как большая часть эпитаксиального слоя $\mathrm{GaN}$ в вертикальном направлении была удалена, его структура приобрела островковый характер, а скорость травления уменьшилась в 2 раза. Это связано с тем, что перенос носителей заряда по поверхности высокоомной Si-подложки затруднен и, таким образом, металл-усиленное фотохимическое травление переходит в обычное фотохимическое, вследствие чего скорость травления резко снижается. Для полного удаления островков слоя $\mathrm{GaN}$ с поверхности $\mathrm{Si}$-подложки требуется значительное время, в течение которого поверхность подложки тоже подвергается воздействию травителя, в результате на ней появляются „ямки травления“, т.е. увеличивается шероховатость поверхности (табл. 2). Так, значение шероховатости травленой поверхности $\mathrm{Si}$-подложки для $\mathrm{Ga}-$ полярного слоя 4 составило $R_{q}=32$ нм, тогда как для $\mathrm{N}$-полярного слоя 2 , длительность травления которого гораздо меньше, $R_{q}=7$ нм.

При СЭМ-исследовании было установлено, что непосредственно вблизи края Ті-маски травление происходит существенно медленнее, чем вдали от него. На рис. 4 приведены для сравнения СЭМ-изображения травленой поверхности двух различных Ga-полярных слоев, на которых видно, что вблизи границы травления (рис. 4, $a, b$ ) толщина и количество островков неудаленного слоя $\mathrm{GaN}$ гораздо больше, чем вдали от границы травления (рис. 4, $c, d$ ). Это можно объяснить тем, что титан растворяется в используемом травителе, 
$a$
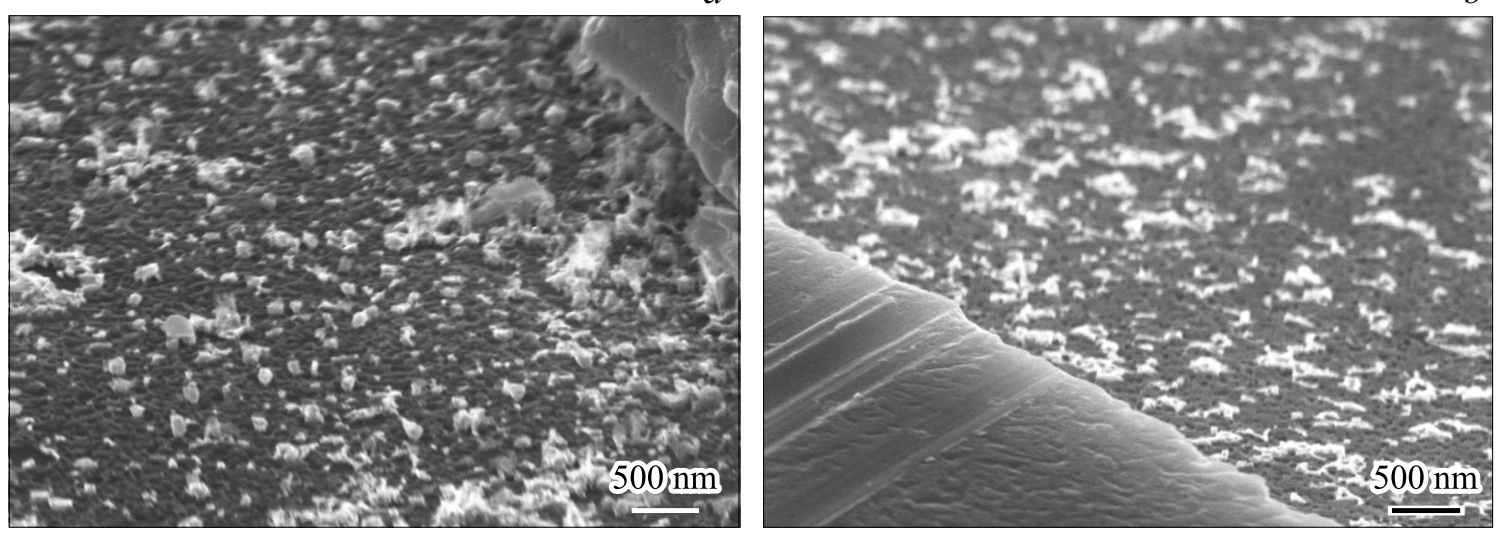
$d$
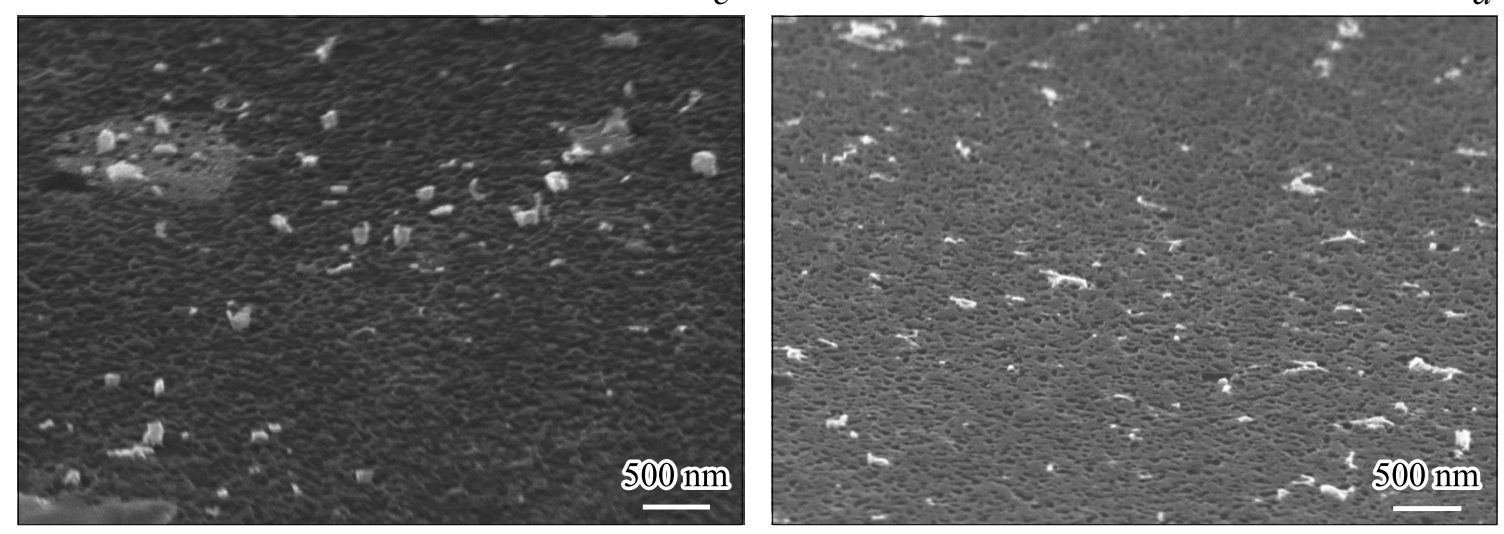

Рис. 4. СЭМ-изображения поверхности слоев после травления с Ті-маской 1 мкм: вблизи границы травления, структура 3 (a) и структура $4(b)$; вдали от границы травления, структура $3(c)$ и структура $4(d)$.

составляя конкуренцию нитриду галлия. Стандартный электродный потенциал $\mathrm{Ti}^{2+} / \mathrm{Ti}$ составляет $-1.63 \mathrm{~B}[17]$, а стандартный электродный потенциал восстановления персульфат-иона $\mathrm{S}_{2} \mathrm{O}_{8}^{2-} / \mathrm{SO}_{4}^{2-}$ равен $+2.01 \mathrm{~B}$, поэтому персульфат-ион $\mathrm{S}_{2} \mathrm{O}_{8}^{2-}$ и тем более радикал $\mathrm{S}_{2} \mathrm{O}_{8}^{*-}$ способен окислить Ті. Таким образом, вблизи границы травления около Ті-маски персульфат-ион $\mathrm{S}_{2} \mathrm{O}_{8}^{2-}$ расходуется одновременно на окисление и слоя $\mathrm{GaN}$, и маски Ti.

В третьей серии экспериментов при условиях, описанных ранее, травлению подверглись образцы структур с нанесенной Au-маской толщиной 200 нм. В результате травления на всех образцах слой $\mathrm{GaN}$ был полностью удален с поверхности Si-подложки. На рис. 5 представлены СЭМ-изображения поверхности после травления с Аu-маской до полного удаления слоя $\mathrm{GaN}$ с поверхности Si-подложки, из которых видно, что, в отличие от результата травления с Ті-маской (рис. 4), количество островков слоя $\mathrm{GaN}$ вблизи границы травления практически не отличается от количества островков слоя $\mathrm{GaN}$ вдали от границы травления. На рис. 5, $a$ и $b$ видно, что в результате фотохимического травления с Аu-маской получен анизотропный профиль травления с вертикальными стенками, а поверхность $\mathrm{Si}-$ подложки практически не повреждена. Отметим, что скорость травления при использовании золотой маски выше, а шероховатость поверхности Si-подложки после удаления слоя $\mathrm{GaN}$ меньше, чем при травлении с Ті-маской (табл. 2). Увеличение скорости травления для образцов структур с Аu-маской может объясняться как различием стандартных электродных потенциалов (для $\mathrm{Ti}^{2+} / \mathrm{Ti}$ он составляет $-1.63 \mathrm{~B}$, в то время как для $\left.\mathrm{Au}^{+} / \mathrm{Au}+1.69 \mathrm{~B}[17]\right)$, так и тем, что благородный металл $(\mathrm{Au})$ катализирует образование сульфат-анионрадикала $\left(\mathrm{SO}_{4}^{*-}\right)$ из персульфат-аниона $\left(\mathrm{S}_{2} \mathrm{O}_{8}^{2-}\right)$ под воздействием УФ излучения. Снижение шероховатости кремниевой подложки после травления связано с увеличением скорости травления слоя $\mathrm{GaN}$ и соответственно уменьшением необходимой для удаления островков $\mathrm{GaN}$ длительности взаимодействия раствора травителя с поверхностью Si-подложки.

Результаты травления пяти образцов слоев $\mathrm{GaN}$ с $\mathrm{Au}$-маской представлены в табл. 2, из которой видно, что так же, как и при травлении с Ті-маской, скорость травления N-полярного слоя с Аu-маской в несколько раз превышает скорость травления Ga-полярных слоев. При этом скорость травления слоя $\mathrm{GaN}$ с N-полярностью почти одинакова при использовании Аu-маски и Ті-маски. Для Gа-полярных образцов скорость травления с маской из благородного металла $(\mathrm{Au})$ в 2-4 раза больше, чем с 
$a$

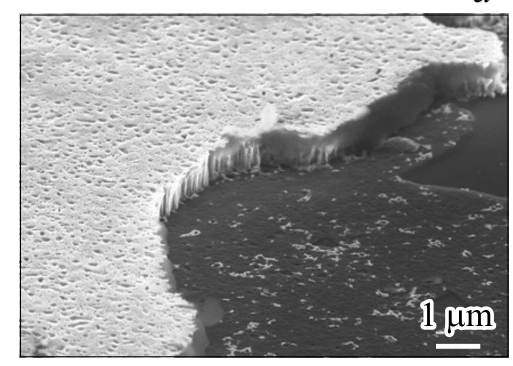

$d$

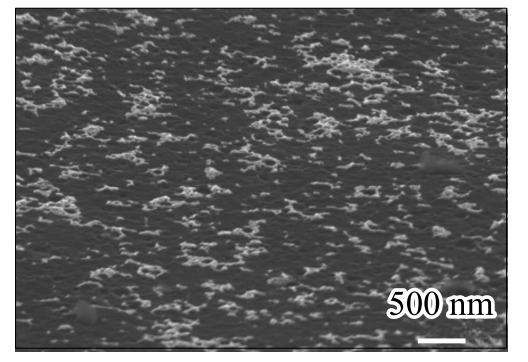

$b$
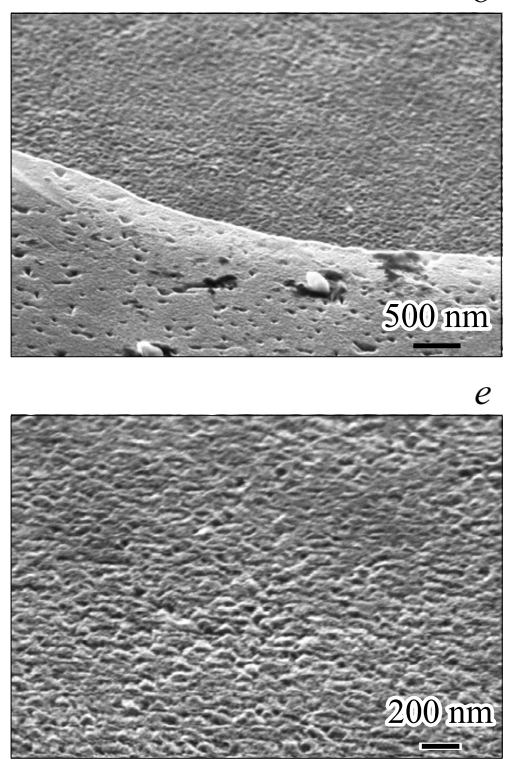

\section{西}
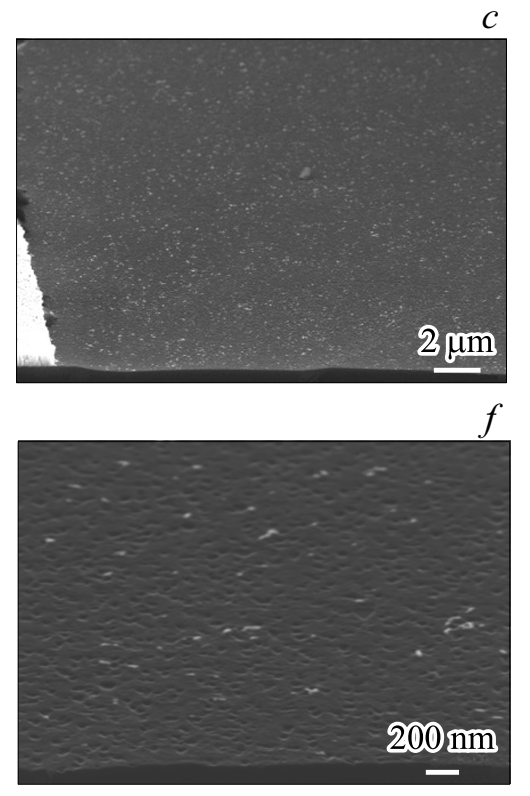

Рис. 5. СЭМ-изображения травленой поверхности с Аu-маской толщиной 200 нм: вблизи границы травления, структура 1 (a), структура $2(b)$, структура $4(c)$; вдали от границы травления, структура $1(d)$, структура $2(e)$, структура $4(f)$.

Ті-маской, что согласуется с результатами, представленными в работе [10].

Увеличение скорости травления структуры 5 по сравнению с аналогичными Ga-полярными структурами $\mathrm{GaN}$ связано с различной исходной морфологией. В данном образце слой $\mathrm{GaN}$ представляет собой не до конца сросшиеся домены с развитой поверхностью, большим количеством пор и протяженных дефектов. В эти поры легко проникает травящий раствор, что увеличивает площадь контакта $\mathrm{GaN}$ с травителем, а значит, и скорость травления.

\section{4. Заключение}

В ходе исследования установлено, что скорость травления слоя $\mathrm{GaN}$ сильно зависит от его полярности и морфологии, а также материала маски. Скорость травления $\mathrm{N}$-полярного слоя $\mathrm{GaN}$ практически одинакова при использовании $\mathrm{Au-маски} \mathrm{и} \mathrm{Ті-маски.} \mathrm{Ско-}$ рость травления Ga-полярных слоев с Аu-маской в 2-4 раза больше, чем при использовании Ті-маски. В результате металл-стимулированного фотохимического травления слоев $\mathrm{GaN}$ с Au-маской получен анизотропный профиль травления с практически чистой гладкой поверхностью Si-подложки. Таким образом, металл-стимулированное фотохимическое травление с $\mathrm{Au}$-маской может быть применено для изготовления приборов на основе слоев $\mathrm{GaN}$.

\section{Финансирование работы}

Ростовые эксперименты проводились в рамках выполнения государственного задания № 16.9789.2017/БЧ.
Морфологические исследования и травление образцов выполнены в рамках генерального соглашения о научноисследовательской деятельности между Сколтехом и СПбАУ РАН (№ 3663-МRА, проект 4).

\section{Конфоликт интересов}

Авторы заявляют, что у них нет конфликта интересов.

\section{Список литературы}

[1] Д.М. Красовицкий, А.Г. Филаретов, В.П. Чалый. Электроника: НТБ, № 8, 113 (2011).

[2] V.J. Gokhale, M. Rais-Zadeh. J. MEMS, IEEE 2013.

[3] I. Ryger, G. Vanko, T. Lalinsky, S. Hascik, A. Bencurova, P. Nemec, R. Andok, M. Tomaska. Sensors Actuators A, 227, 55 (2015).

[4] A.C. Tamboli, M.C. Schmidt, SiddharthRajan, J.S. Speck, U.K. Mishra, S.P. DenBaars, E.L. Hu. J. Electrochem. Soc., 156 (1), 47 (2009).

[5] J.A. Bardwell, J.B. Webb, H. Tang, J. Fraser, S. Moisa. J. Appl. Phys., 89 (7), 4142 (2001).

[6] C. Youtseya, I. Adesida, G. Bulman. Appl. Phys. Lett., 71 (15), 2151 (1997).

[7] D.H. van Dorp, J.L. Weyher, M.R. Kooijman, J.J. Kelly. J. Electrochem. Soc., 156 (10), 371 (2009).

[8] L. Ma, K. Fareen Adeni, Chang Zeng, Yawei Jin, K. Dandu, Y. Saripalli, M. Johnson, D. Barlage. CS MANTECH Conf. (Vancouver, Canada, 2006) p. 105.

[9] G. Parish, P.A. Scali, S.M.R. Spaargaren, B.D. Nener. Proc. SPIE, 4592 (2001). DOI: 10.1117/12.448955

[10] J.M. Hwang, K.Y. Ho, Z.H. Hwang, W.H. Hung, Kei May Lau, H.-L. Hwang. Superlat. Microstr., 35, 45 (2004).

[11] J.L. Weyher, F.D. Tichelaar, D.H. van Dorp, J.J. Kelly, A. Khachapuridz. J. Cryst. Growth, 312, 2607 (2010). 
[12] Y. Gao, M.D. Craven, J.S. Speck, S.P. DenBaars, E.L. Hu. Appl. Phys. Lett., 84 (17), 3322 (2004).

[13] D. Zhuang, J.H. Edgar. Mater. Sci. Engin. R, 48, 1 (2005).

[14] J.E. Borton, C. Cai, M.I. Nathan, P. Chow, J.M. Van Hove, A. Wowchak, H. Morkoc. Appl. Phys. Lett., 77 (8), 1227 (2000).

[15] S. Adachi. Properties of Semiconductor Alloys: Group-IV, III-V and II-VI Semiconductors (John Wiley \& Sons, Ltd, 2009).

[16] Н.М. Эмануэль, М.Г. Кузьмина. Экспериментальные методы химической кинетики (М., Изд-во Моск. ун-та, 1985).

[17] В.А. Рабинович, 3.Я. Хавин. Краткий химический справочник (Л., Химия, 1991).

[18] A.M. Mizerov, S.N. Timoshnev, M.S. Sobolev, E.V. Nikitina, K.Yu. Shubina, T.N. Berezovskaia, I.V. Shtrom, A.D. Bouravleuv. Semiconductors, 52 (12), 1529 (2018).

Редактор Л.В. Шаронова

\section{The metal-assisted photochemical etching of $\mathbf{N}$ - and Ga-face epitaxial GaN layers}

D.V. Mokhov' ${ }^{1}$, T.N. Berezovskaya ${ }^{\mathbf{1}, 2}$, E.V. Nikitina ${ }^{1}$, K.Yu. Shubina ${ }^{1}$, A.M. Mizerov ${ }^{1}$, A.D. Bouravlev 1,2,3

${ }^{1}$ St. Petersburg National Research Academic University, Russian Academy of Sciences,

194021 St. Petersburg, Russia

${ }^{2}$ loffe Institute,

194021 St. Petersburg, Russia

${ }^{3}$ St. Petersburg Electrotechnical University "LETl“,

197376 St. Petersburg, Russia

Abstract The results of photochemical etching without the application of external voltage, for structures with Ga- and N-polar GaN layers synthesized by molecular beam epitaxy with plasma activation of nitrogen are presented. It is shown that the etching rate of layers with different polarities is very different. In this case, the use of gold-based masks for etching of GaN layers instead of titanium also makes it possible to increase the etching rate of the layers. 